\title{
Decreased plasma levels of nitric oxide derivatives in obstructive sleep apnoea: response to CPAP therapy
}

R Schulz, D Schmidt, A Blum, X Lopes-Ribeiro, C Lücke, K Mayer, H Olschewski, W Seeger, F Grimminger

\begin{abstract}
Background-Reduced endothelium dependent vasodilation has been reported in patients with obstructive sleep apnoea (OSA) but direct measurements of the most potent naturally occurring vasodilator, nitric oxide (NO) or its derivatives (nitrate and nitrite, $\mathrm{NO}_{\mathrm{x}}$ ), have not yet been performed in these patients.

Methods-In 21 patients with OSA of mean (SE) age 54 (2) years, body mass index (BMI) $30.9(1.1) \mathrm{kg} / \mathrm{m}^{2}$, and apnoeahypopnoea index (AHI) 37 (4)/h, NO levels were measured in peripheral venous blood samples by chemiluminescence. Blood samples were obtained before and after two nights of continuous positive airway pressure (CPAP) and after 5.5 (1.5) months of follow up. Thirteen age matched, healthy volunteers and 18 patients without OSA but with a similar spectrum of comorbidity served as controls (control groups 1 and 2).

Results-Before CPAP NO levels were $21.7(1.5) \mu M$ in patients with OSA compared with $42.6(2.2) \mu M$ and 36.7 (1.7) $\mu M$ in control groups 1 and 2 , respectively ( $p<0.01$ for each comparison). $\mathrm{NO}_{\mathrm{x}}$ concentrations increased to 32.1 (2.7) $\mu \mathrm{M}$ after two nights of CPAP and remained constant at $32.9(2.3) \mu M$ at follow up $(p<0.01$ compared with levels before CPAP).
\end{abstract}

Division of Pulmonary and Critical Care

Medicine, Department of Internal Medicine, Justus-Liebig

University, 35392

Gießen, Germany

R Schulz

D Schmidt

A Blum

$\mathrm{X}$ Lopes-Ribeiro

C Lücke

K Mayer

H Olschewski

W Seeger

F Grimminger

Correspondence to: Dr R Schulz

Received 22 December 1999 Returned to authors 20 March 2000

Revised manuscript received

24 May 2000

Accepted for publication

8 August 2000
Conclusions-Plasma NO levels are reduced in OSA and can be increased by short and long term CPAP therapy. Although the precise mechanism underlying this observation remains to be clarified, it may have important implications for the development of cardiovascular disease in patients with OSA and for the life saving effect of CPAP.

(Thorax 2000;55:1046-1051)

Keywords: obstructive sleep apnoea; nitric oxide; CPAP therapy

Obstructive sleep apnoea (OSA) is associated with cardiovascular disorders such as arterial hypertension, coronary artery disease, and cerebrovascular disease. ${ }^{1}$ It is thought that this accounts for the increased mortality observed in patients with OSA, ${ }^{23}$ but the causal relationship between OSA and cardiovascular disease remains to be fully established. ${ }^{4}$
One hypothesis to explain this association is based on the concept of disturbed vascular control in OSA. ${ }^{5}$ Nitric oxide (NO) is the main vasodilating substance released from the endothelium. Deficiency of NO has been implicated in the pathogenesis of cardiovascular disease. ${ }^{67}$ Two studies have already suggested reduced endothelium dependent vasodilation in OSA. Carlson and colleagues administered intra-arterial acetylcholine and sodium nitroprusside infusions to 16 awake patients with OSA and measured forearm blood flow using venous occlusion plethysmography. ${ }^{8}$ They found that endothelium dependent vascular relaxation was impaired independently of hypertension. Duchna et al recently demonstrated reduced vascular responsiveness to bradykinin and nitroglycerin after intravenous infusion in 10 of 12 patients with OSA using the dorsal hand vein technique. ${ }^{9}$ After one month of treatment with continuous positive airway pressure (CPAP) vascular reactivity was reversed to normal in all subjects with an abnormal initial response.

Direct measurements of NO or its derivatives have, however, not yet been performed in patients with OSA. Because NO is a gas with a very short plasma half life of only a few seconds, it is difficult to measure NO itself. More feasible is the measurement of the more stable derivatives of $\mathrm{NO}$ (nitrate and nitrite $\left(\mathrm{NO}_{\mathrm{x}}\right)$ ) in biological fluids. $\mathrm{NO}_{\mathrm{x}}$ concentrations not only depend on endothelial NO formation but also on other aspects of NO metabolism such as the distribution in various body compartments and the rate of elimination by the kidneys. Nevertheless, $\mathrm{NO}_{\mathrm{x}}$ levels have been suggested as the most appropriate measure of overall NO production. ${ }^{10}$ The aim of the present study was therefore to determine plasma levels of $\mathrm{NO}_{\mathrm{x}}$ in a group of patients with OSA before and after CPAP therapy.

\section{Methods}

STUDY POPULATION

Twenty one consecutive patients with OSA were investigated. All gave written informed consent and the study protocol was approved by the local ethics committee.

In all patients serum creatinine (normal $<1.2 \mathrm{mg} / \mathrm{dl}$ ), total cholesterol (normal $<200 \mathrm{mg} / \mathrm{dl}$ ), and fasting blood glucose levels (normal $<110 \mathrm{mg} / \mathrm{dl}$ ) were measured. The patients were asked about their regular medications and smoking habits. The medical history of the patients was evaluated with special refer- 
Table 1 Characteristics of subjects in the OSA group and control group 2

\begin{tabular}{llll}
\hline & OSA $(n=21)$ & Control group 2 $(n=18)$ & p value \\
\hline Sex $(\mathrm{M} / \mathrm{F})$ & $17 / 4$ & $12 / 6$ & \\
$\mathrm{Age}(\mathrm{years})$ & $54(2)$ & $61(2)$ & $<0.05$ \\
$\mathrm{BMI}\left(\mathrm{kg} / \mathrm{m}^{2}\right)$ & $30.9(1.1)$ & $25.5(1.1)$ & $<0.05$ \\
$\mathrm{AHI}(\mathrm{n} / \mathrm{hour})$ & $37(4)$ & - & \\
$\mathrm{SaO}_{2}<90 \%(\%$ of TST) & $23.9(5.4)$ & $1.2(2.0)$ & \\
$\mathrm{Mean} \mathrm{SaO}_{2}(\%)$ & $91.8(0.7)$ & $94.5(1.4)$ & \\
$\mathrm{Minimum} \mathrm{SaO}_{2}(\%)$ & $66.1(2.9)$ & $84.3(2.5)$ & \\
Arterial hypertension & $12(57 \%)$ & $7(39 \%)$ & $\mathrm{NS}$ \\
Coronary artery disease & $1(5 \%)$ & $2(11 \%)$ & $\mathrm{NS}$ \\
Cerebrovascular disease & $2(10 \%)$ & $3(17 \%)$ & $\mathrm{NS}$ \\
Diabetes mellitus & $1(5 \%)$ & $3(17 \%)$ & $\mathrm{NS}$ \\
Chronic renal failure & - & - & $\mathrm{NS}$ \\
Hypercholesterolaemia & $7(33 \%)$ & $5(28 \%)$ & $\mathrm{NS}$ \\
Smoking & $8(38 \%)$ & $8(44 \%)$ & \\
ACE inhibitors & $4(19 \%)$ & $5(28 \%)$ & \\
\hline
\end{tabular}

Data are given as mean (SE) or as total numbers.

$\mathrm{BMI}=$ body mass index; $\mathrm{AHI}=$ apnoea-hypopnoea index; $\mathrm{SaO}_{2}=$ nocturnal oxygen saturation TST $=$ total sleep time; NS = not significant.

ence to cardiovascular disease (arterial hypertension, coronary artery disease, and cerebrovascular disease). Blood pressure at rest was measured at fixed time intervals during their stay in the sleep laboratory at $06.00,12.00$, 16.00 , and 20.00 hours. Arterial hypertension was diagnosed if blood pressure values exceeded $140 / 90 \mathrm{~mm} \mathrm{Hg}$ during at least two different measurements or if there was known and medically treated hypertension. Patients taking oral nitrate preparations were excluded from the study.

Thirteen healthy non-smoking volunteers (nine men) of mean (SE) age 53 (2) years and body mass index (BMI) $27.9(0.4) \mathrm{kg} / \mathrm{m}^{2}$ comprised control group 1 and 18 patients without OSA admitted to hospital with other diagnoses served as control group 2. The main diagnosis in these patients was lung cancer, followed by other bronchopulmonary diseases such as pneumonia and chronic bronchitis.

In the control subjects OSA was excluded by a negative history of sleep related symptoms (snoring, witnessed apnoeas, excessive daytime sleepiness) and overnight pulse oximetry recordings. The characteristics of the OSA group and control group 2 are shown in table 1 .

POLYSOMNOGRAPHY

Polysomnography was performed on three consecutive nights. The electroencephalogram (electrodes at positions C3-A2 and C4-A1 of the international 10-20 system), electrooculogram and electromyogram of the submandibular and pretibial muscles were simultaneously recorded. Ventilatory airflow at the nose and mouth was registered with thermistors, and the breathing movements of the chest and abdomen were monitored by inductive plethysmography. Oxygen saturation $\left(\mathrm{SaO}_{2}\right)$ was measured transcutaneously by pulse oximetry at the finger tip of the patient. Finally, an electrocardiogram was obtained. All data were stored on a computerised polysomnograph with capability for analogue registration (Sidas GS, IfM GmbH, Wettenberg, Germany). Analysis of sleep stages was performed manually at 30 second intervals according to the criteria of Rechtschaffen and Kales. ${ }^{11}$

An obstructive apnoea was defined as complete cessation of oronasal flow in the presence of thoracoabdominal breathing move- ments. If neither oronasal flow nor breathing efforts of the chest and abdomen could be detected, this was defined as a central apnoea. Hypopnoea was defined as a reduction in the respiratory amplitude of more than $50 \%$ with regard to the preceding effort signals. All apnoeas and hypopnoeas were required to have a duration of at least 10 seconds. The apnoeahypopnoea index (AHI) was obtained by dividing the total number of apnoeas and hypopnoeas by the total sleep time (TST). An AHI of more than 10 per hour of sleep was considered diagnostic of OSA.

During the first night a diagnostic study was performed. After confirming the diagnosis of OSA, CPAP therapy was given to all patients during the second night (Aria LX, Respironics Inc, Germany). On the third night all patients slept with the finally titrated pressure to assure adequate elimination of all apnoeas, hypopnoeas, and snoring.

After using CPAP at home for a variable length of time (range 92-265 days) the patients were re-examined in our sleep laboratory. Compliance with CPAP therapy was evaluated by the readings on the time counter built into the CPAP machine. Acceptable compliance was defined as CPAP use of at least five hours per night for five days of the week. On the control night the adequacy of the initially chosen CPAP pressure was checked and increased if snoring or apnoeas were again detected, otherwise it was kept constant or decreased if possible.

DETERMINATION OF $\mathrm{NO}_{\mathrm{x}}$ PLASMA LEVELS At 07.00 hours, immediately after polysomnography, a peripheral venous blood sample was withdrawn into a tube prepared with EDTA and centrifuged at $2000 \mathrm{rpm}$ for 10 minutes. The supernatant plasma was stored in a refrigerator at $-20^{\circ} \mathrm{C}$. Blood samples were obtained before and after initiating CPAP treatment (after the first two nights of CPAP therapy and at follow up). $\mathrm{NO}_{\mathrm{x}}$ levels were determined using a chemiluminescence technique as previously described. ${ }^{12}$

Briefly, the plasma samples were deproteinated and double volumes of $0.5 \mathrm{M} \mathrm{NaOH}$ and zinc sulphate $(30 \%)$ were added to the samples. The mixture was shaken continuously for 15 minutes at $600 \mathrm{rpm}$ and thereafter centrifuged for 10 minutes at $13000 \mathrm{rpm}$. The protein free supernatant was put into Eppendorf cups, two portions each of $600 \mu \mathrm{l}$. The samples were injected into a heated reaction chamber at a constant flow $\left(98^{\circ} \mathrm{C} ; 600 \mu \mathrm{l} / \mathrm{min}\right)$ and the chamber was filled with a solution of vanadium (III) chloride $0.1 \mathrm{M}$ in $2 \mathrm{M} \mathrm{HCl}$ which quantitatively reduced the NO decomposition products (nitrate and nitrite) back to NO. Oxygen free nitrogen at a flow rate of $160 \mathrm{ml} / \mathrm{min}$ was used to carry the $\mathrm{NO}$ through a cooling tower to a chemiluminescence NO analyser (UPK 3100; UPK, Bad Nauheim, Germany) where NO reacted with ozone to produce $\mathrm{NO}_{2}$. The energy of the $\mathrm{NO}_{2}$ emitted photons was filtered, enhanced by a photomultiplier, and converted into a voltage signal. The NO concentrations (in $\mathrm{ppb}$ ) were calculated 
from the intensity of this signal after prior calibration with defined gases (NO in oxygen free nitrogen; Messer Griesheim, Herborn, Germany). The NO levels were continuously monitored on a personal computer with the help of a program developed by one of the authors (KM). The maximal increases in the concentrations of the two different probes were averaged and converted to $\mu \mathrm{M} \mathrm{NO}$ in the original plasma samples using a calibration curve obtained from prior measurements of calibration samples containing known concentrations of nitrate and nitrite.

The average $\mathrm{NO}_{\mathrm{x}}$ concentration in control group 1 was interpreted as the normal reference value for $\mathrm{NO}_{\mathrm{x}}$. An increase in $\mathrm{NO}_{\mathrm{x}}$ after CPAP was defined as a change in $\mathrm{NO}$ concentrations of more than $2 \mu \mathrm{M}$. This cut off value was chosen because the day to day variability of $\mathrm{NO}_{x}$ between individuals had been found to lie within this range in earlier experiments.

STATISTICAL ANALYSIS

All data are given as mean (SE) values. The plasma levels of $\mathrm{NO}_{x}$ in the two control groups and in the OSA group were compared using the Wilcoxon-Mann-Whitney test. Differences in $\mathrm{NO}_{\mathrm{x}}$ values in individuals before and after CPAP therapy were evaluated by the two tailed paired Wilcoxon test in the whole OSA group as well as in normotensive and hypertensive patients with OSA. Differences in plasma concentrations of $\mathrm{NO}_{\mathrm{x}}$ between the OSA group and the controls and between patients with OSA before and after CPAP were further quantified by calculating the HodgesLehmann estimator including 95\% confidence intervals (CI). While performing calculations, the family wise error rate was taken into consideration. A p value of $<0.05$ was regarded as significant.

\section{Results}

PATIENT CHARACTERISTICS

In the OSA group 12 subjects suffered from concomitant cardiovascular disease (mainly systemic arterial hypertension). All patients had normal renal function and only one patient suffered from diabetes mellitus. Seven patients had mild hypercholesterolaemia (200-220 mg/ dl). Four patients were being treated with an ACE inhibitor and eight were habitual smokers.

The healthy control group 1 was age matched with the OSA group, but the average BMI was somewhat lower than in the patients with OSA. Compared with the OSA group, patients in control group 2 were slightly older but were not overweight. In this group the percentage of hypertensive patients was lower $(39 \%$ vs $57 \%, \mathrm{p}<0.05)$. The other characteristics did not differ significantly between the OSA group and control group 2 .

POLYSOMNOGRAPHIC DATA

The 21 patients who participated in the study had moderate to severe OSA with markedly disturbed sleep architecture (data not shown). After starting CPAP therapy the AHI de-

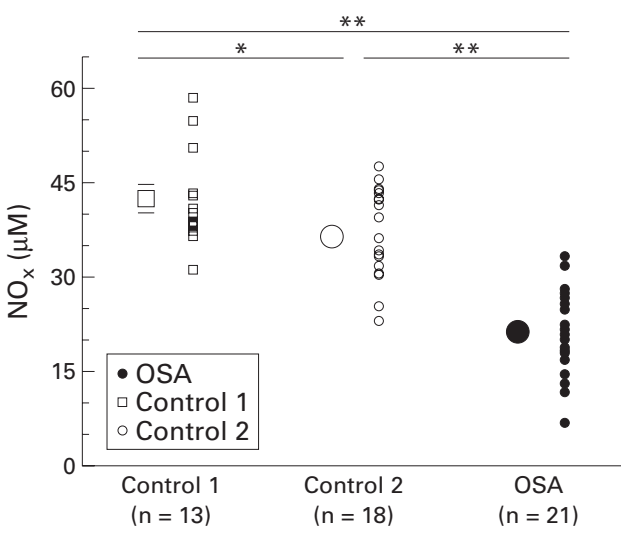

Figure 1 Plasma levels of nitric oxide derivatives (NO) in untreated OSA patients and control groups 1 (healthy volunteers) and 2 (patients without OSA). All data are given as mean (SE) and as individual values. The SE is not depicted if it is so small that it would be obscured by the symbol of the mean value. ${ }^{\star} p<0.05,{ }^{\star *} p<0.01$.

creased to $<10 / \mathrm{h}$ in all patients and nocturnal oxygen saturation was markedly improved or even normalised. The mean CPAP pressure was set at $10.0(2.4) \mathrm{cm} \mathrm{H}_{2} \mathrm{O}$.

After a mean follow up period of 5.5 (1.5) months 15 patients were re-evaluated by polysomnography. Thirteen patients were compliant with CPAP (average use 7.1 (1.8) h per night) and reported improvement in their daytime sleepiness. One patient had been unable to sleep with her CPAP machine for two weeks before admission because of upper respiratory tract infection. One patient was non-compliant with CPAP (average use $3.5 \mathrm{~h}$ per night). These two patients were excluded from statistical analysis. During the control night the CPAP pressure was kept constant in nine patients, had to be increased in four patients, and was reduced in two patients. Six patients were lost to follow up either because of non-compliance (four patients), intervening severe illness (one patient), or long distance to their place of residence (one patient).

$\mathrm{NO}_{\mathrm{x}}$ PLASMA LEVELS BEFORE CPAP

Mean plasma levels of $\mathrm{NO}_{\mathrm{x}}$ were 42.6 (2.2) $\mu \mathrm{M}$ in the healthy control group 1 compared with 36.7 (1.7) $\mu \mathrm{M}$ in control group $2(\mathrm{p}<0.05$, fig 1). In the OSA group the mean $\mathrm{NO}_{x}$ level was further reduced to 21.7 (1.5) $\mu \mathrm{M}$, which was highly significant compared with the two control groups $(p<0.01$ for each comparison; Hodges-Lehmann estimators $-19.7 \mu \mathrm{M}(95 \%$ CI -12.7 to -28.0$)$ and $-15.1 \mu \mathrm{M}(95 \%$ CI -8.7 to -22.0 ) respectively, fig 1 ).

When looking at individual data, all patients with OSA had lower $\mathrm{NO}_{x}$ levels than the mean values of both control groups although there was some overlap between $\mathrm{NO}_{x}$ levels in patients with OSA and controls (fig 1). The presence of hypertension had no effect on $\mathrm{NO}_{\mathrm{x}}$ levels in the patients with OSA $(21.4(2.3) \mu \mathrm{M}$ in hypertensive vs 22.2 (1.7) $\mu \mathrm{M}$ in normotensive patients; fig 2).

$\mathrm{NO}_{\mathrm{x}}$ PLASMA LEVELS AFTER CPAP After two nights of CPAP therapy $\mathrm{NO}_{x}$ levels increased to a mean of $32.1(2.7) \mu \mathrm{M}(\mathrm{p}<0.01$ compared with before CPAP; Hodges- 

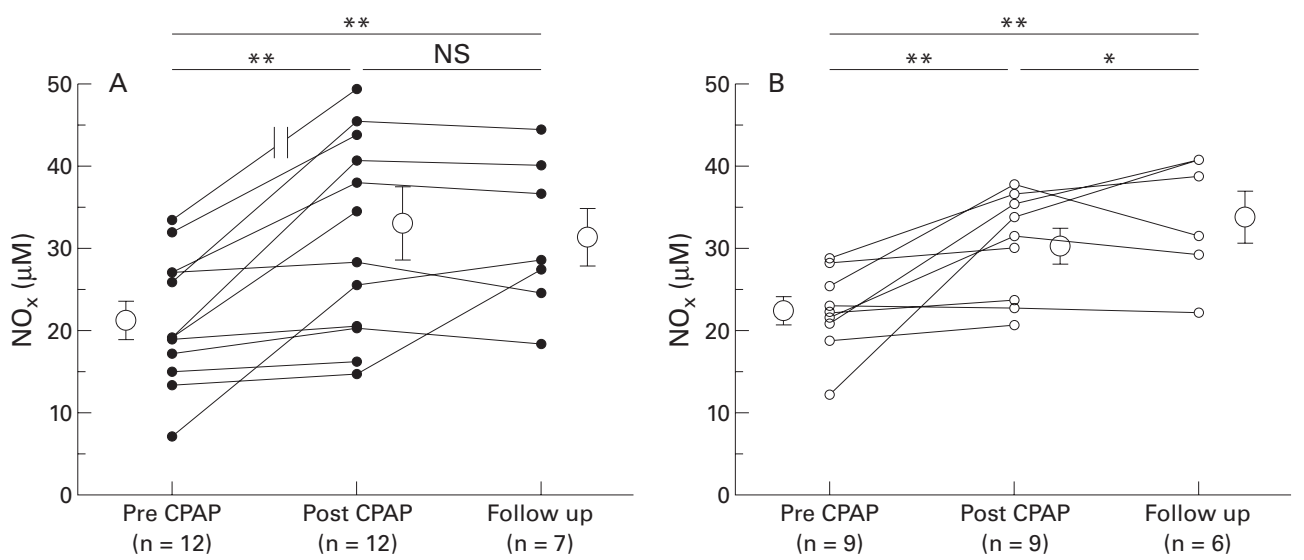

Figure 2 Plasma levels of nitric oxide derivatives $\left(N O_{\nu}\right)$ in $(A)$ hypertensive and $(B)$ normotensive patients with OSA before CPAP, after two nights of CPAP, and at follow up. All data are given as mean (SE) and as individual values. ${ }^{\star} p<0.05 ;{ }^{\star *} p<0.01 ; N S=$ non-significant.

Lehmann estimator $10.1 \mu \mathrm{M}(95 \%$ CI 2.6 to 16.9)). The $\mathrm{NO}_{\mathrm{x}}$ levels remained unchanged in eight patients $(38 \%)$ but increased in 13 patients $(62 \%)$. The increase in $\mathrm{NO}_{x}$ concentrations was more pronounced in hypertensive patients than in normotensive patients (33.6 (4.5) $\mu \mathrm{M}$ vs 30.2 (2.2) $\mu \mathrm{M}, \mathrm{p}<0.05$, fig 2 ).

At follow up $\mathrm{NO}_{\mathrm{x}}$ levels remained constant (mean 32.9 (2.3) $\mu \mathrm{M} ; \mathrm{p}<0.01$ compared with pre-CPAP values; Hodges-Lehmann estimator $12.4 \mu \mathrm{M}$ (95\% CI 3.6 to 21.0)). Compared with levels before CPAP therapy, individual $\mathrm{NO}_{\mathrm{x}}$ levels were still reduced in three patients $(23 \%)$ but had increased in the remaining 10 patients $(77 \%)$. In the OSA patients with hypertension $\mathrm{NO}_{\mathrm{x}}$ levels did not change significantly during the follow up period (32.2 (3.5) $\mu \mathrm{M}$, fig $2 \mathrm{~A}$ ). The normotensive patients with OSA had a small but significant further increase in $\mathrm{NO}_{\mathrm{x}}$ levels (33.8 (3.1) $\mu \mathrm{M}, \mathrm{p}<0.05$ compared with the level after two nights of CPAP, fig 2B).

\section{Discussion}

In this study plasma levels of $\mathrm{NO}_{\mathrm{x}}$ were found to be markedly reduced in a group of 21 untreated patients with OSA. After two nights of CPAP therapy $\mathrm{NO}_{x}$ levels increased in more than half of the patients. After a mean follow up period of 5.5 months an even higher percentage of those patients regularly using their CPAP device had increased $\mathrm{NO}_{\mathrm{x}}$ levels.

Blood samples for the measurement of $\mathrm{NO}_{x}$ were taken in the morning shortly after waking. Since nitrate and nitrite have a plasma half life of 4-7 hours, ${ }^{10}$ the $\mathrm{NO}_{\mathrm{x}}$ concentrations achieved reflect $\mathrm{NO}$ generation during the night while the patients were asleep. It is also crucial to the understanding of our results that a recent study has found a significant correlation between changes in forearm blood flow as measured by venous occlusion plethysmography and the serum nitrite concentration. ${ }^{13}$ The current observation of reduced plasma levels of $\mathrm{NO}_{\mathrm{x}}$ in patients with OSA thus suggests reduced endothelium dependent vascular relaxation, as previously assumed for this disease. $^{89}$

The healthy control group had the highest mean $\mathrm{NO}_{\mathrm{x}}$ level, subjects in control group 2 had intermediate $\mathrm{NO}_{\mathrm{x}}$ levels, and the OSA patients had the lowest mean $\mathrm{NO}_{\mathrm{x}}$ levels of all groups. There are many variables that can influence $\mathrm{NO}_{\mathrm{x}}$ levels which have to be considered when discussing these observations. Arterial hypertension, diabetes mellitus, chronic renal failure, hypercholesterolaemia, smoking, and aging have all been shown to be associated with decreased plasma levels of $\mathrm{NO}_{\mathrm{x}}{ }^{14-19} \mathrm{On}$ the other hand, drugs such as nitrates and ACE inhibitors directly or indirectly increase the generation of $\mathrm{NO}$ in the vasculature..$^{20}$

One might argue that the reduction in $\mathrm{NO}_{\mathrm{x}}$ was the result of the higher percentage of arterial hypertension in the OSA group compared with control group 2. However, the $\mathrm{NO}_{\mathrm{x}}$ concentrations were also low in those OSA patients without concomitant hypertension. This observation is in agreement with the study by Carlson et al who reported that endothelium dependent vascular relaxation was reduced in OSA independently of hypertension. ${ }^{8}$

It is very unlikely that metabolic disturbances had a major impact on the levels of $\mathrm{NO}_{x}$ in our study. Only a few patients suffered from diabetes mellitus and all had normal serum creatinine concentrations. Total cholesterol levels were not in the range known to be linked with decreased $\mathrm{NO}_{\mathrm{x}}$ concentrations. ${ }^{17}$

Smoking might negatively affect plasma levels of $\mathrm{NO}_{\mathrm{x}}{ }^{18}$ but it has to be kept in mind that blood samples were withdrawn at 07.00 hours - that is, after some hours without inhalation of cigarette smoke. It is known that NO production decreases with advancing age. ${ }^{19}$ The OSA group was age matched with the healthy control group, whereas patients in control group 2 were older. Thus, the difference between the OSA group and control group 2 might be regarded as even more significant. Finally, the influence of drugs on $\mathrm{NO}_{\mathrm{x}}$ levels has to be considered. Nitrates were not taken by any of the subjects studied, but a similar number of patients in the OSA group and in control group 2 were receiving ACE inhibitors. These drugs may actually lead to an increase in $\mathrm{NO}_{\mathrm{x}}$ concentrations, ${ }^{21}$ thereby possibly attenuating the true difference in $\mathrm{NO}_{\mathrm{x}}$ levels between the OSA group and the healthy control group. 
The patients in control group 2 all suffered from bronchopulmonary disease. In the presence of airway inflammation, bronchopulmonary disorders might be associated with high levels of exhaled $\mathrm{NO} .{ }^{22}$ However, these changes do not usually affect the intravascular compartment-that is, plasma levels of $\mathrm{NO}_{\mathrm{x}} \cdot{ }^{23}{ }^{24}$ Furthermore, most of our patients were free from infection at the time of the investigation.

A possible limitation of our study is that the patients did not adhere to a low nitrate/nitrite diet which has been recommended for the measurement of $\mathrm{NO}_{\mathrm{x}} \cdot{ }^{10}$ Unfortunately, it was not feasible to submit all the patients in the sleep laboratory to such a diet so we are not able to exclude a confounding influence of the individual diet on the level of $\mathrm{NO}_{\mathrm{x}}$. A further potential limitation to our study is that the control subjects were not followed up to have repeated measurements of $\mathrm{NO}_{\mathrm{x}}$. However, we think it unlikely that $\mathrm{NO}_{\mathrm{x}}$ levels would have risen in all or most of these subjects to an extent comparable to the OSA patients after CPAP. Finally, methodological factors such as nitrite contamination of the blood tubes containing $\mathrm{EDTA}^{25}$ or the influence of the tourniquet pressure applied during bleeding ${ }^{26}$ might have biased our results. Unfortunately, it was impossible to control for these confounding factors but they were presumably of equal importance in all subjects studied.

Taken together, the difference in $\mathrm{NO}_{\mathrm{x}}$ levels between the two control groups might be attributed to the lack of cardiovascular disease in the healthy volunteers while the further reduction in $\mathrm{NO}_{\mathrm{x}}$ levels in the OSA group is assumed to be caused by the sleep related breathing disorder itself. A final argument for the validity of our results is that effective CPAP therapy led to a rapid and long lasting increase in $\mathrm{NO}_{\mathrm{x}}$ concentrations in patients with OSA.

From the present study it is not possible to explain the mechanism of $\mathrm{NO}_{\mathrm{x}}$ reduction in OSA. However, it might be speculated that intermittent nocturnal oxygen desaturation and/or apnoea related haemodynamic changes are of major importance.

In patients with OSA nocturnal hypoxaemia might adversely affect the metabolic balance between production and breakdown of endothelium derived NO. NO is synthesised from the amino acid L-arginine by $\mathrm{NO}$ synthases. It is rapidly metabolised to its oxidative products nitrate, nitrite, and peroxynitrite. Both the synthesis and breakdown of $\mathrm{NO}$ are critically dependent on the presence of oxygen, either in its free or haemoglobin bound form. The formation of peroxynitrite occurs primarily under pathological conditions by the interaction of $\mathrm{NO}$ with superoxide anions.

There is some evidence that hypoxaemia associated with apnoea could lead to decreased production of NO. Firstly, oxygen is a cosubstrate of NO synthase. Secondly, recent data, as yet only published in abstract form, suggest that NO synthase inhibitors are significantly increased in patients with OSA. ${ }^{27}$ Thirdly, and most important, hypoxia suppresses both the transcriptional rate of the
eNOS gene and the stability of its mRNA. ${ }^{28} 29$ Finally, free oxygen radicals which have been shown to accumulate in untreated OSA patients ${ }^{30}$ might cause an exaggerated destruction of NO.

During each apnoea the blood pressure gradually rises, thereby imposing increased shear stress to the vessel wall. Shear stress primarily enhances NO release from the endothelium causing vasodilation. ${ }^{31}$ Chronic exposure of the vascular bed to high shear and pressure forces in OSA might, however, ultimately lead to endothelial damage and dysfunction with reduced release of $\mathrm{NO}$ and consecutive paradoxical vasoconstriction. ${ }^{32}$ The increase in $\mathrm{NO}_{\mathrm{x}}$ after the initiation of CPAP would then reflect the amelioration of OSA related blood pressure changes induced by this form of treatment.

It is important to point out that Duchna et al did not find restoration of vascular responsiveness in patients with OSA after the infusion of nitroglycerin. ${ }^{9}$ This suggests that defects in the second messenger systems activated by $\mathrm{NO}$ might contribute to the loss of endothelium dependent vascular relaxation in OSA. Such disturbances might thus add to the currently observed reduction in NO generation in patients with OSA.

The findings of the present study may have clinically important implications. The deficiency in the NO system might contribute to the development of hypertension and atherosclerosis, and thereby to the emergence of cardiovascular disease in OSA. CPAP treatment is believed to normalise life expectancy in patients with OSA by its favourable influence on the progression of cardiovascular disorders. ${ }^{23}$ However, the mechanisms responsible for this beneficial effect of CPAP therapy are not well understood, and hitherto the evidence that CPAP reduces cardiovascular morbidity and mortality has come primarily from epidemiological observations. ${ }^{33}$ Since NO deficiency has an important role in the pathogenesis of cardiovascular disease, we hypothesise that the increase in $\mathrm{NO}_{\mathrm{x}}$ levels which occurs after starting CPAP therapy might constitute one mechanism by which CPAP therapy saves life in patients with OSA.

In conclusion, plasma levels of nitric oxide derivatives are significantly reduced in OSA and may be increased by both short and long term CPAP treatment. Although the precise mechanism underlying this observation remains to be fully elucidated, it may have important implications for the development of cardiovascular disease in patients with OSA and for the life saving effect of CPAP.

This work contains part of the doctoral thesis of C Lücke. It was supported by a research grant from Respironics Inc, Germany.

1 Weiss JW, Launois SH, Anand A, et al. Cardiovascular morbidity in obstructive sleep apnea. Prog Cardiovasc Dis 1999;41:367-76.

$2 \mathrm{He}$ J, Kryger $\mathrm{MH}$, Zorick FJ, et al. Mortality and apnea index in obstructive sleep apnea (experience in 385 male patients). Chest 1988;94:9-14.

3 Partinen M, Jamieson A, Guilleminault CG. Long-term Partinen M, Jamieson A, Guilleminault CG. Long-term outcome for obstructive sleep apt
mortality. Chest 1988;94:1200-4.

4 Wright J, Johns R, Watt I, et al. The health effects of obstructive sleep apnoea and the effectiveness of treatment 
with continuous positive airways pressure: a systematic review of the research evidence. BMF 1997;314:851-60.
5 Hedner J. Vascular function in OSA. Sleep 1996;19:S213-7. 6 Loscalzo J, Welch G. Nitric oxide and its role in the cardioLoscalzo J, Welch G. Nitric oxide and its role in the cardiar system. Prog Cardiovasc Dis 1995;38:87-104.
vasculat

7 vascular system. Prog Cardiovasc Dis 1995;38:87-104. Cohen RA. The role of nitric oxide and other endotheliumderived vasoactive substances
Cardiovasc Dis 1995;38:105-28.

8 Carlson JT, Rangemark C, Hedner JA. Attenuated endothelium-dependent vascular relaxation in patients with sleep apnea. F Hypertens $1996 ; \mathbf{1 4}: 577-84$

9 Duchna HW, Guilleminault C, Stoohs RA, et al. Vascular reactivity in obstructive sleep apnea syndrome. Am f Respir Crit Care Med 2000;161:187-91.

10 Viinikka L. Nitric oxide as a challenge for the clinical chemistry laboratory. Scand 7 Clin Lab Invest 1996;56:577-81.

11 Rechtschaffen A, Kales A, eds. A manual of standardized terminology, techniques and scoring system for sleep stages of minology, techniques and scoring system for sleep stages of National Institute of Neurological Disease and Blindness, 1968 .

12 Spriestersbach R, Grimminger $\mathrm{F}$, Weissmann $\mathrm{N}$, et al. On-line measurement of nitric oxide generation in buffer-perfused lungs: release into both the intravascular and alveolar compartment. I Appl Physiol 1995;78:1502-8.

13 Kelm M, Preik-Steinhoff H, Preik M, et al. Serum nitrite sensitively reflects endothelial NO formation in human forearm vasculature : evidence for biochemical assessmen of the endothelial L-arginine-NO pathway. Cardiovasc Res 1999;41:765-72.

14 Node K, Kitakaze M, Yoshikawa H, et al. Reduced plasma concentrations of nitrogen oxide in individuals with essential hypertension. Hypertension 1997;30:405-8.

15 Huszka M, Kaplar M, Rejto L, et al. The association of reduced endothelium derived relaxing factor-NO production with endothelial damage and increased in vivo platelet tion 1997;86:173-80.

16 Blum M, Yachnin T, Wollman Y, et al. Low nitric oxide production in patients with chronic renal failure. Nephron duction in pa

17 Tanaka S, Yashiro A, Nakashima Y, et al. Plasma nitrate/nitrite level is inversely correlated with plasma lowdensity lipoprotein cholesterol level. Clin Cardiol 1997;20: $361-5$

18 Node $\mathrm{K}$, Kitakaze M, Yoshikawa $\mathrm{H}$, et al. Reversible reduction in plasma concentration of nitric oxide induced by cigarette smoking in young adults. Am f Cardiol 1997;79: $1538-41$

19 Marin J. Age-related changes in vascular responses: a review. Mech Ageing Dev 1995;79:71-114.
20 Fung HL, Chung SJ, Bauer JA, et al. Biochemical mechanism of oranic nitrate action Am 7 Cardiol 1992;70:4-10B.

21 Kohno M, Yokokawa K, Minami M, et al. Plasma levels of nitric oxide and related vasoactive factors following long-term treatment with angiotensin-converting enzyme inhibitor in patients with essential hypertension. Metabolism 1999;48:1256-9.

22 Barnes PJ, Kharitonov SA. Exhaled nitric oxide: a new lung function test. Thorax 1996;51:233-7.

23 Jang AS, Choi IS. Nitric oxide metabolites in patients with asthma: induced sputum versus blood. Respir Med 1999;93: $912-8$.

24 Ahren C, Jungersten L, Sandberg T. Plasma nitrate as an index of nitric oxide formation in patients with acute infectious disease. Scand $\mathcal{F}$ Infect Dis 1999;31:405-7.

25 Tsikas D, Gutzki FM, Rossa S, et al. Measurement of nitrite and nitrate in biological fluids by gas chromatographymass spectrometry and by the Griess assay: problems with the Griess assay - solutions by gas chromatography-mass spectrometry. Anal Biochem 1997;244:208-20.

26 Yagi M, Adachi J, Tatsuno Y, et al. Change in nitric oxide in humans due to application of a pneumatic tourniquet. Clin humans due to application of

27 Carlson J, Hedner J, Pettersson A. Increased plasma concentration of ADMA, a naturally occurring nitric oxide synthesis inhibitor, in OSA patients. Am $\mathcal{f}$ Respir Crit Care Med 1997;155:A869.

28 McQuillan LP, Leung GK, Marsden PA, et al. Hypoxia inhibits expression of eNOS via transcriptional and post-transcriptional mechanisms. Am f Physiol 1994;267: H1921-7.

29 Liao JK, Zulueta JJ, Yu FS, et al. Regulation of bovine endothelial constitutive nitric oxide synthase by oxygen. $f$ Clin Invest 1995;96:2661-6.

30 Schulz R, Mahmoudi S, Hattar K, et al. Enhanced release of superoxide from polymorphonuclear neutrophils in obstructive sleep apnea: impact of CPAP therapy. Am f Respir Crit Care Med 2000;162:566-70.

31 Ranjan V, Xiao Z, Diamond SL. Constitutive NOS expression in cultured endothelial cells is elevated by fluid shear sion in cultured endothelial cells is ele

32 Ziegler T, Bouzourene K, Harrison VJ, et al. Influence of oscillatory and unidirectional flow environments on the expression of endothelin and nitric oxide synthase in cultured endothelial cells. Arterioscler Thromb 1998;18:68692

33 Peker Y, Hedner J, Johansson A, et al. Reduced hospitalization with cardiovascular and pulmonary disease in obstructive sleep apnea patients on nasal CPAP treatment. Sleep 1997;20:645-53. 